\title{
Prevalence of malocclusion and occlusal traits in the early mixed dentition in Shanghai, China
}

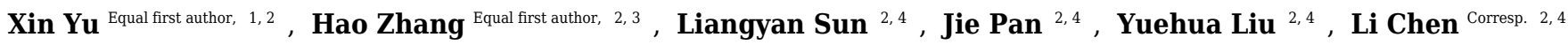 \\ ${ }^{1}$ Department of Pediatric Dentistry, Shanghai Stomatological Hospital, Fudan University, Shanghai, China \\ 2 Oral Biomedical Engineering Laboratory, Shanghai Stomatological Hospital, Fudan University, Shanghai, China \\ 3 Department of Preventive Dentistry, Shanghai Stomatological Hospital, Fudan University, Shanghai, China \\ 4 Department of Orthodontics, Shanghai Stomatological Hospital, Fudan University, Shanghai, China \\ Corresponding Author: Li Chen \\ Email address: lichen_kq@fudan.edu.cn
}

Background. Epidemiological data on malocclusion among Chinese children are scant. The aim of this study was to provide detailed information on the prevalence of malocclusion in early mixed dentition children in Shanghai, China.

Methods. A cross-sectional survey was conducted from September 2016 to April 2017, and 2810 children aged 7 - to 9 - years were selected from 10 primary schools by cluster random sampling. Several occlusal parameters, including Angle molar relationship, overjet, overbite, open bite, anterior and posterior crossbite, midline displacement, scissors bite, and teeth crowding and spacing, were clinically registered by five calibrated orthodontic dentists.

Results. We found that $79.4 \%$ children presented one or more occlusal anomalies. Angle Class I, Class II and Class III molar relationship were recorded in $42.3 \%, 50.9 \%$ and $5.9 \%$ of the sample, respectively. The proportion of Class III increased from $5.0 \%$ at age 7 to $7.8 \%$ at age 9 . In the sagittal plane, increased overjet $>3 \mathrm{~mm}$ was observed in $40.8 \%$ subjects, while the prevalence of severe overjet ( $>8 \mathrm{~mm}$ ), anterior edge-to-edge (zero overjet) and anterior crossbite were $5.2 \%, 8.1 \%$ and $10.5 \%$, respectively. Vertically, deep overbite $>2 / 3$ overlap was found in $6.2 \%$ of the children and open bite in $4.3 \%$. Boys exhibited a higher rate of overbite than girls. For the transversal occlusal anomalies, $36.1 \%$ of the children had a midline displacement, which was followed by posterior crossbite $(2.6 \%)$ and scissors bite (1.0\%). Teeth space discrepancies were also common anomalies and anterior crowding (>2 mm) affecting $28.4 \%$ of the children, while anterior spacing ( $>4 \mathrm{~mm}$ ) affecting $9.5 \%$. Girls showed a higher prevalence of anterior crowding and a lower frequency of teeth spacing than boys.

Conclusions. Our study demonstrated that malocclusion is prevalent among children in the early mixed dentition, and more health resources should be warranted to meet the challenge of prevention or early intervention of malocclusion. 


\section{Prevalence of malocclusion and occlusal traits in the early mixed}

\section{2 dentition in Shanghai, China}

3

4 Xin Yu†' ${ }^{1}$, Hao Zhang† ${ }^{2,3}$, Liangyan Sun ${ }^{3,4}$, Jie Pan ${ }^{3,4}$, Yuehua Liü3,4, Li Chen*3,4

7 1. Department of Pediatric Dentistry, Shanghai Stomatological Hospital, Fudan University,

8 Shanghai 200001, China

9 2. Department of Preventive Dentistry, Shanghai Stomatological Hospital, Fudan University, 10 Shanghai 200001, China

11 3. Oral Biomedical Engineering Laboratory, Shanghai Stomatological Hospital, Fudan

12 University, Shanghai 200001, China

13 4. Department of Orthodontics, Shanghai Stomatological Hospital, Fudan University, Shanghai

14 200001, China

$17 *$ Corresponding author

18 Li Chen, Email: lichen_kq@fudan.edu.cn

19

20

† These authors contributed equally to this work. 


\section{Prevalence of malocclusion and occlusal traits in the early mixed \\ 23 dentition in Shanghai, China}

25 Abstract

Background. Epidemiological data on malocclusion among Chinese children are scant. The aim of this study was to provide detailed information on the prevalence of malocclusion in early mixed dentition children in Shanghai, China.

Methods. A cross-sectional survey was conducted from September 2016 to April 2017, and 2810 children aged 7- to 9- years were selected from 10 primary schools by cluster random sampling. Several occlusal parameters, including Angle molar relationship, overjet, overbite, open bite, anterior and posterior crossbite, midline displacement, scissors bite, and teeth crowding and spacing, were clinically registered by five calibrated orthodontic dentists.

Results. We found that $79.4 \%$ children presented one or more occlusal anomalies. Angle Class I, Class II and Class III molar relationship were recorded in $42.3 \%, 50.9 \%$ and $5.9 \%$ of the sample, respectively. The proportion of Class III increased from $5.0 \%$ at age 7 to $7.8 \%$ at age 9 . In the sagittal plane, increased overjet $>3 \mathrm{~mm}$ was observed in $40.8 \%$ subjects, while the prevalence of severe overjet ( $>8 \mathrm{~mm}$ ), anterior edge-to-edge (zero overjet) and anterior crossbite were 5.2\%, $8.1 \%$ and $10.5 \%$, respectively. Vertically, deep overbite $>2 / 3$ overlap was found in $6.2 \%$ of the children and open bite in $4.3 \%$. Boys exhibited a higher rate of overbite than girls. For the transversal occlusal anomalies, $36.1 \%$ of the children had a midline displacement, which was followed by posterior crossbite $(2.6 \%)$ and scissors bite $(1.0 \%)$. Teeth space discrepancies were also common anomalies and anterior crowding $(>2 \mathrm{~mm})$ affecting $28.4 \%$ of the children, while anterior spacing (>4 mm) affecting 9.5\%. Girls showed a higher prevalence of anterior crowding and a lower frequency of teeth spacing than boys. 
46 Conclusions. Our study demonstrated that malocclusion is prevalent among children in the early

47 mixed dentition, and more health resources should be warranted to meet the challenge of

48 prevention or early intervention of malocclusion.

Keywords: Malocclusion; Prevalence; Early mixed dentition; Angle classification; Overjet; Open bite; Crossbite; Crowding, Spacing

\section{Introduction}

Malocclusion is one of the most common oral disorders among children, and it affects not only the oral masticatory function but also the craniofacial development and facial appearance. Children with certain malocclusion traits appear to have more problems related to psychology and social interactions, and even their quality of life suffers when they reach adulthood (MartinsJunior et al. 2012; Nguyen et al. 1999; Stenvik et al. 2011). For this reason, malocclusion is regarded as an emerging public health issue.

The mixed dentition is an important developmental stage to the undisturbed occlusal relationship. The eruption of the first permanent molar plays a critical role in maintaining the interarch space and the sagittal occlusal relationship. Several longitudinal observations have revealed that a substantial number of malocclusions occur during this period (Dimberg et al. 2015; Dimberg et al. 2013; Gois et al. 2012), and the accumulated evidence has indicated that early intervention starting from the mixed dentition would benefit the youngsters with Class III malocclusion, crossbite, crowding and posterior crossbite (Gianelly 2002; Keski-Nisula et al. 2008; Lippold et al. 2013; Mitani 2002).

Epidemiological information is essential for developing strategies and plans to promote oral health. In China, national or local surveys on dental caries and periodontitis have been carried out regularly ( $\mathrm{Li} \&$ Wang 2014; Zhou et al. 2018). However, there is still insufficient information 
70

71

72

73

74

75

76

77

78

79

80

81

82

83

84

85

86

87

88

89

90

91

92

93

94

on the prevalence of malocclusions. Recently, we made an effort to investigate the malocclusion status of Shanghai preschool children and an extraordinarily high prevalence, $83.9 \%$, was found (Zhou et al. 2017). In the current study, another cross-sectional survey was carried out to assess the prevalence of malocclusion and the distribution of occlusal traits among school children at the stage of early mixed dentition in Shanghai.

\section{Materials and Methods}

\section{Study sample}

For the period of September 2016 to April 2017, a cluster random sampling was applied in this study. In brief, we chose five administrative districts in Shanghai city: three of them in the urban area (Hongkou, Putuo, and Jing'an districts) and two in the suburbs (Pudong and Minhang districts). Then, two primary schools in each district were randomly selected, and the students with the following characteristics were identified as candidates of this survey: (1) aged 7 to 9 years; (2) without a history of orthodontic treatment; (3) without craniofacial diseases; and (4) consensual participation of the children and their parents. In all, 2810 children, including 1479 boys and 1331 girls, were recruited.

The protocol of this study was approved by the Ethics Committee of Shanghai Stomatological Hospital, Fudan University (Approval Number: 2015-0012). Written informed consent was signed by the parents of all the children who participated in the survey.

\section{Oral examination}

The oral examination was carried out by five calibrated orthodontic dentists. The children were examined at schools, using portable lighting and disposable mouth mirrors. Sagittal molar relationships by Angle classification, degree of overjet and overbite, anterior and posterior crossbite, and teeth crowding and spacing were recorded (Table 1).

The children who presented one or more of the following indications were registered as malocclusion: Angle Class III, increased overjet ( $>3 \mathrm{~mm}$ ), anterior crossbite, anterior edge-to- 
95

96

97

98

99

100

101

102

103

104

105

106

107

108

109

110

111

112

113

114

115

116

117

118

119

120

edge, deep overbite ( $>2 / 3$ overlap), open bite, midline displacement, posterior crossbite, posterior edge-to-edge, scissors bite, anterior or posterior crowding $(>2 \mathrm{~mm})$, and anterior spacing ( $>4$ $\mathrm{mm})$.

\section{Reliability of examinations}

Twenty subjects were evaluated by the five examiners independently of each other. One of the examiners was an orthodontist with more than fifteen years' clinic experience, and the other four examiners compared their results to the senior orthodontist's data respectively. Interexaminer reliability was determined by calculating Cohen's kappa coefficient, and the values were $>0.68$.

\section{Statistical analysis}

The rates of occlusal characteristics and malocclusion were reported by age and gender. The chi-squared test and Fisher's exact probability method were applied to determine the statistical associations between the independent variables and the malocclusion variable. Cohen's kappa value was used to measure the agreement among examiners. The data were input using the Epidata software and analyzed using SPSS Statistics 22 (IBM, Armonk NY, USA). The level of significance was set at $p<.05$.

\section{Results}

The overall prevalence of malocclusion among school children aged 7 - 9 years in Shanghai was $79.4 \%$ (2231/2810), and only $20.6 \%$ of them had normal occlusion (Table 2 ). The boys had a very similar rate of malocclusion to that of the girls. No significant difference was observed between age groups $(p>.05)$.

The distribution of the sagittal occlusal features among the children in Shanghai is shown in Table 3. The relationship of the first molars was classified according to the Angle classification; $42.3 \%$ children showed a Class I relationship, $50.9 \%$ children were Class II, and 5.9\% were Class III. An increasing trend in the rate of Angle Class III with age was observed, from 5.0\% at age 7 to $7.8 \%$ at age 9 . The increased overjet was prevalent (40.8\%), and most of the cases were 
121 mild or moderate, but $5.2 \%$ of the children were found to have a severe overjet. Approximately 122 one-tenth of the children had an anterior crossbite.

123 Table 4 depicts the vertical and transversal occlusal anomalies. The probability of the deep 124 overbite of the anterior teeth was $43.8 \%$ and that of severe overbite was $6.2 \%$. Boys were more 125 prone to deep overbite than girls $(p=.003)$. The rate of open bite of anterior teeth was $4.24 \%$; it 126 decreased with age, from $4.9 \%$ at age 7 to $2.7 \%$ at age 9 . With respect to transversal anomalies, $12736.1 \%$ of the children were found to have a midline displacement, and $2.6 \%$ had posterior crossbite. The prevalence of a scissors bite was relatively low (0.9\%), but it increased with age.

Teeth crowding and spacing were prevalent among the children (Table 5). The prevalence of anterior crowding of $>2 \mathrm{~mm}$ of the maxillary or mandibular teeth was $13.3 \%$ and $22.5 \%$, respectively. In all, $28.4 \%$ of the children presented anterior crowding. Posterior crowding was less common, and only $0.2 \%$ of the subjects were found to have maxillary posterior crowding of $>2 \mathrm{~mm}$, and $1.0 \%$ was mandibular posterior. The rate of anterior spacing of $>4 \mathrm{~mm}$ of the maxillary teeth was $8.0 \%$, and that of the mandibular teeth was 3.0\%. An increasing trend with age was observed for the rate of crowding of the upper anterior teeth, and the boys' probability of anterior crowding, either of the maxillary or of the mandibular teeth, was lower than that of the girls' $(p<.001)$.

\section{Discussion}

The prevalence of malocclusion in different populations ranges from $21 \%$ to $90 \%$ (Grippaudo et al. 2013; Perillo et al. 2010; Perinetti et al. 2008; Shalish et al. 2013; Thilander et al. 2001), and this huge variation may largely be attributed to the discrepancies in the definitions of malocclusion and the methodologies applied. We found that the prevalence of malocclusion in early mixed dentition in Shanghai was as high as $79.4 \%$, which was considerably higher than the rate of $71.2 \%$ among children with mixed dentition in a national survey in 2000 (Fu et al. 2002). This result was similar to the rate of malocclusion in the deciduous dentition, i.e., $83.9 \%$, in the 
146 Shanghai area (Zhou et al. 2017). Our findings confirmed that malocclusion was one of the most 147 common health problems in children and adolescents.

148

149

150

151

152

153

154

155

156

157

158

159

160

161

162

163

164

165

166

167

168

169

170

171

Deep overbite $(>1 / 3$ overlap, prevalence $43.8 \%)$ and increased overjet $(>3 \mathrm{~mm}$, prevalence $40.8 \%$ ) were the two most common types of occlusion abnormalities in Shanghai schoolchildren. The high rates of overbite and overjet were also reported in Nigeria (deep overbite: $31.7 \%$ and increased overjet: 44.6\%) (daCosta et al. 2016) and in China's western city Xi'an (deep overbite $37.6 \%$ and increased overjet 35.0\%) (Zhou et al. 2016). Nevertheless, compared to the fact that $63.7 \%$ of the preschool children were found to have deep overbite in Shanghai (Zhou et al. 2017), it was less frequent in the age group considered in this study. This decline could be partly explained by the self-correction of deep overbite during dental development (Dimberg et al. 2015). The increased overjet ( $>3 \mathrm{~mm}$ ) occurred more frequently in the early mixed dentition $(43.8 \%)$ than in the primary stage (33.9\%) (Zhou et al. 2017). However, in terms of severe increased overjet ( $>8 \mathrm{~mm}$ ), the change was substantial: $0.9 \%$ for primary and $5.2 \%$ for mixed dentition. This change may increase the risk of oral trauma (Nguyen et al. 1999).

Anterior crowding and anterior crossbite were another two high-incidence malocclusions observed in this study. In contrast to deep overbite, crowding and crossbite are less likely to be self-corrected without any intervention or treatment. Anterior crowding of $>2 \mathrm{~mm}$ was recorded in $28.4 \%$ of the subjects, considerably more frequent than the proportion in primary dentition in the city (Zhou et al. 2017). Moreover, the crowding problem might be worse in the permanent dentition stage, as the arch length decreased during the transition from the mixed to the permanent dentition (Gianelly 2002). It was noteworthy that anterior crowding was more prevalent in the mandible $(22.5 \%)$ than maxilla (13.3\%) in Shanghai children, which was consistent in what was found among children in the early mixed dentition in Germany (Tausche et al. 2004) and adolescents in the permanent dentition in Japan (Komazaki et al. 2012).

However, in Iran and Turkey, adolescents had more crowding in the maxilla than mandible (Borzabadi-Farahani et al. 2009; Gelgor et al. 2007). 
172

173

174

175

176

177

178

179

180

181

182

183

184

185

186

187

188

189

190

191

192

193

194

195

196

197

198

The prevalence of anterior crossbite in Shanghai children was comparable to that in Israeli (9.5\%) (Shalish et al. 2013), German (7.7\%) (Tausche et al. 2004), and Iranian (8.4\%)

(Borzabadi-Farahani et al. 2009) children. Nevertheless, only $2.6 \%$ of the children had a posterior crossbite, which was relatively less frequent comparing the rates in Canada (15\%) (Karaiskos et al. 2005), Brazil (13.3\%) (Almeida et al. 2011) and Israel (23.3\%) (Shalish et al. 2013). Several studies have pointed out that Chinese adults have a higher prevalence of Angle Class III malocclusion than the other racial groups (Lew et al. 1993; Soh et al. 2005; Woon 1988); however, we found that this rate was acceptable in Shanghai children, even though it was slightly lower than in children from some other Asian countries (Borzabadi-Farahani et al. 2009; Komazaki et al. 2012). We found about 50 percent of the children had an Angle Class II molar relationship, and the rate was much higher than those reported in German (28\%) (Tausche et al. 2004), Brazil (21.4\%) (Dias \& Gleiser 2009), Israel (29.9\%) (Shalish et al. 2013) and Sweden (28\%) (Dimberg et al. 2013). A high prevalence of Angle Class II, namely 38.2\%, was also reported among 12-15-year-old adolescents in Japan (Komazaki et al. 2012), and it seemed that East Asians were more prone to have Angle Class II.

Although there was no difference of overall prevalence of malocclusion between boys and girls, several sexual dimorphisms were identified in the current study. It seemed that boys were more likely to have overbite than girls, and this finding was supported by previous studies in Germany, France, Turkey and Brazil (Dias \& Gleiser 2009; Gelgor et al. 2007; Lux et al. 2009; Souames et al. 2006). Nevertheless, anterior crowding was more prevalent among girls than boys, which was consistent with what was found in Japan and Colombia (Komazaki et al. 2012; Thilander et al. 2001). These dimorphisms might be explained by the differences in skeletal maturity and/or eruption of permanent teeth (Lux et al. 2009).

$$
\text { Despite the reported benefit of early intervention of malocclusion (Dimberg et al. 2013; }
$$
Keski-Nisula et al. 2008; Proffit 2006), the high prevalence of malocclusion did not mean that most children were subjected to orthodontic treatment. Since these children were in the "ugly duckling" stage, and they probably suffered transient malocclusions, and some of them, such as 
199

200

201

202

203

204

205

206

207

208

209

210

211

212

213

214

215

216

217

218

219

220

221

222

223

224

225

maxillary midline diastema, increased overjet, deep overbite, crowding and even Angle Class II molar relationship, might be spontaneously corrected (Dimberg et al. 2015; Huang \& Creath 1995; Kapur et al. 2018). On the other hand, treatment priorities may vary depending on the severity of malocclusions. Therefore, many investigators have considered the orthodontic treatment need indices such as the Index of Orthodontic Treatment Need (IOTN) in epidemiological studies (daCosta et al. 2016; Komazaki et al. 2012; Shalish et al. 2013;

Steinmassl et al. 2017; Tausche et al. 2004; Thilander et al. 2001). Even though the assessment of the orthodontic treatment need was not the major aim of the current survey, we attempted to obtain a rough estimate of this need on the basis of the criteria of IOTN's Grade 4 and Grade 5 and found that $26.2 \%$ of the children exhibited one or more of the following conditions (Table S1): Angle Class III, increased overjet $>8 \mathrm{~mm}$, anterior crossbite, open bite $>3 \mathrm{~mm}$, posterior crossbite, scissors bite, and anterior or posterior crowding $>4 \mathrm{~mm}$. This rate was consistent with that in the Germans (26.2\%) (Tausche et al. 2004), the Iranians (23\%) (Borzabadi-Farahani et al. 2009), and the Austrians (30.6\%) (Steinmassl et al. 2017).

A strict cluster random sampling was conducted, and a good representation was obtained in this study. Since this survey was school-based, it was infeasible to obtain the treatment records from the children who had a history of orthodontic intervention, and we excluded them because we did not know their original occlusal traits which had already been changed. Although many investigators did so in previous epidemiological studies (Komazaki et al. 2012; Lagana et al. 2013; Souames et al. 2006; Thilander et al. 2001), it should be kept in mind that this exclusion may introduce some representativeness bias. However, to the best of our knowledge, very few children under the age of 10 years appeal to orthodontists for malocclusion in Shanghai, the effects of the exclusion may be limited. Actually, in the current study, no more than one per cent of the subjects had received orthodontic treatment, which was less than the rate reported in French children (Souames et al. 2006).

A large number of young people meet the criteria for early orthodontic treatment, and this is a huge challenge for our health system. Besides early treatment, establishing effective policies 
226

227

228

229

230

231

232

233

234

235

236

237

238

239

240

241

242

243 244

245

246

247

248

249

250

251

252

to prevent the occurrence of malocclusion may be another choice. Multiple factors, including genetic, environmental, and social-behavioral factors, play a role in the development of malocclusion. (Grippaudo et al. 2016; Laganà et al. 2013). Some feeding habits and oral habits are believed to be important causes of malocclusion, and sucking habits are associated with anterior open bite and posterior crossbite (Agarwal et al. 2014; Boronat-Catala et al. 2017; Gungor et al. 2016). Therefore, attention needs to be paid to malocclusion disorders, and early health education and behavior intervention may contribute to a reduction of the burden of malocclusion.

\section{Conclusions}

Our cross-sectional study demonstrated that $79.4 \%$ of the children in the stage of mixed dentition had one or more malocclusion traits. For the prevention and intervention of malocclusion, substantial resources and efforts are warranted from orthodontists, health policy makers, communities, and, of course, families.

\section{Acknowledgments}

The authors would like to express their sincere gratitude to all the workers of the five Preventive Dental Clinics in the Hongkou, Putuo, Jing'an, Pudong, and Minhang districts for supporting this study. We thank LetPub for its linguistic assistance during the preparation of this manuscript.

\section{Reference}

Agarwal SS, Nehra K, Sharma M, Jayan B, Poonia A, and Bhattal H. 2014. Association between breastfeeding duration, non-nutritive sucking habits and dental arch dimensions in deciduous dentition: a cross-sectional study. Prog Orthod 15:59. DOI 10.1186/s40510-014-0059-4.

Almeida MR, Pereira ALP, Almeida RR, Almeida-Pedrin RR, and Silva Filho OG. 2011. Prevalence of malocclusion in children aged 7 to 12 years. Dental Press J Orthod $16: 123-131$. 
253

254

255

256

257

258

259

260

261

262

263

264

265

266

267

268

269

270

271

272

273

274

275

276

277

278

279

Boronat-Catala M, Montiel-Company JM, Bellot-Arcis C, Almerich-Silla JM, and Catala-

Pizarro M. 2017. Association between duration of breastfeeding and malocclusions in primary and mixed dentition: a systematic review and meta-analysis. Sci Rep 7:5048. DOI 10.1038/s41598-017-05393-y.

Borzabadi-Farahani A, Borzabadi-Farahani A, and Eslamipour F. 2009. Malocclusion and occlusal traits in an urban Iranian population. An epidemiological study of 11to 14-year-old children. Eur J Orthod 31:477-484. DOI 10.1093/ejo/cjp031.

daCosta 00, Aikins EA, Isiekwe GI, and Adediran VE. 2016. Malocclusion and early orthodontic treatment requirements in the mixed dentitions of a population of Nigerian children. J Orthod Sci 5:81-86. DOI 10.4103/2278-0203.186164.

Dias PF, and Gleiser R. 2009. Orthodontic treatment need in a group of 9-12-year-old Brazilian schoolchildren. Braz Oral Res 23:182-189.

Dimberg L, Lennartsson B, Arnrup K, and Bondemark L. 2015. Prevalence and change of malocclusions from primary to early permanent dentition: a longitudinal study. Angle Orthod 85:728-734. DOI 10.2319/080414-542.1.

Dimberg L, Lennartsson B, Soderfeldt B, and Bondemark L. 2013. Malocclusions in children at 3 and 7 years of age: a longitudinal study. Eur J Orthod 35:131-137. DOI 10.1093/ejo/cjr110.

Fu M, Zhang D, and Wang B. 2002. The prevalence of malocclusion in China - an investigation of 25,392 children [in Chinese]. Chin J Stomatol 37:371-373.

Gelgor IE, Karaman AI, and Ercan E. 2007. Prevalence of malocclusion among adolescents in central anatolia. Eur J Dent 1:125-131.

Gianelly AA. 2002. Treatment of crowding in the mixed dentition. Am J Orthod Dentofacial Orthop 121:569-571. DOI 10.1067/mod.2002.124172.

Gois EG, Vale MP, Paiva SM, Abreu MH, Serra-Negra JM, and Pordeus IA. 2012. Incidence of malocclusion between primary and mixed dentitions among Brazilian children. A 5-year longitudinal study. Angle Orthod 82:495-500. DOI 
280

281

282

283

284

285

286

287

288

289

290

291

292

293

294

295

296

297

298

299

300

301

302

303

304

305

306

10.2319/033011-230.1.

Grippaudo C, Pantanali F, Paolantonio EG, Grecolini ME, Saulle R, La Torre G, and Deli

R. 2013. Prevalence of malocclusion in Italian schoolchildren and orthodontic treatment need. Eur J Paediatr Dent 14:314-318.

Grippaudo C, Paolantonio EG, Antonini G, Saulle R, La Torre G, and Deli R. 2016. Association between oral habits, mouth breathing and malocclusion. Acta Otorhinolaryngol Ital 36:386-394. DOI 10.14639/0392-100X-770.

Gungor K, Taner L, and Kaygisiz E. 2016. Prevalence of Posterior Crossbite for Orthodontic Treatment Timing. J Clin Pediatr Dent 40:422-424. DOI 10.17796/10534628-40.5.422.

Huang WJ, and Creath CJ. 1995. The midline diastema: a review of its etiology and treatment. Pediatr Dent 1995 17:171-179.

Kapur A, Chawla HS, Utreja A, and Goyal A. 2018. Guiding the Child's Teeth with Class III Dental Malocclusion into Correct Occlusion: A Clinician's Parenting. J Clin Pediatr Dent 42:72-78. DOI 10.17796/1053-4628-42.1.13.

Karaiskos N, Wiltshire WA, Odlum O, Brothwell D, and Hassard TH. 2005. Preventive and interceptive orthodontic treatment needs of an inner-city group of 6- and 9year-old Canadian children. J Can Dent Assoc 71:649.

Keski-Nisula K, Hernesniemi R, Heiskanen M, Keski-Nisula L, and Varrela J. 2008. Orthodontic intervention in the early mixed dentition: a prospective, controlled study on the effects of the eruption guidance appliance. Am J Orthod Dentofacial Orthop 133:254-260. DOI 10.1016/j.ajodo.2006.05.039.

Komazaki Y, Fujiwara T, Ogawa T, Sato M, Suzuki K, Yamagata Z, and Moriyama K. 2012. Prevalence and gender comparison of malocclusion among Japanese adolescents: a population-based study. J World Fed Orthod 1:e67-e72. DOI 10.1016/j.ejwf.2012.07.001.

Lagana G, Masucci C, Fabi F, Bollero P, and Cozza P. 2013. Prevalence of malocclusions, 
307

308

309

310

311

312

313

314

315

316

317

318

319

320

321

322

323

324

325

326

327

328

329

330

331

332

333

oral habits and orthodontic treatment need in a 7- to 15-year-old schoolchildren population in Tirana. Prog Orthod 14:12. DOI 10.1186/2196-1042-14-12.

Lew KK, Foong WC, and Loh E. 1993. Malocclusion prevalence in an ethnic Chinese population. Aust Dent J 38:442-449.

Li C, and Wang Y. 2014. Status of oral health service needs, demands and utilization of Shanghai residents [in Chinese]. J Shanghai Jiao Tong University (Medical Science) 34:206-210.

Lippold C, Stamm T, Meyer U, Végh A, Moiseenko T, Danesh G. 2013. Early treatment of posterior crossbite--a randomised clinical trial.Trials 14:20. DOI 10.1186/17456215-14-20.

Lux CJ, Ducker B, Pritsch M, Komposch G, and Niekusch U. 2009. Occlusal status and prevalence of occlusal malocclusion traits among 9-year-old schoolchildren. Eur J Orthod 31:294-299. DOI 10.1093/ejo/cjn116.

Martins-Junior PA, Marques LS, and Ramos-Jorge ML. 2012. Malocclusion: social, functional and emotional influence on children. J Clin Pediatr Dent 37:103-108.

Mitani H. 2002. Early application of chincap therapy to skeletal Class III malocclusion. Am J Orthod Dentofacial Orthop 121:584-585. DOI 10.1067/mod.2002.124170.

Nguyen QV, Bezemer PD, Habets L, and Prahl-Andersen B. 1999. A systematic review of the relationship between overjet size and traumatic dental injuries. Eur J Orthod 21:503-515. DOI 10.1016/S0889-5406(00)70044-8.

Perillo L, Masucci C, Ferro F, Apicella D, and Baccetti T. 2010. Prevalence of orthodontic treatment need in southern Italian schoolchildren. Eur J Orthod 32:49-53. DOI 10.1093/ejo/cjp050.

Perinetti G, Cordella C, Pellegrini F, and Esposito P. 2008. The prevalence of malocclusal traits and their correlations in mixed dentition children: results from the Italian OHSAR Survey. Oral Health Prev Dent 6:119-129.

Proffit WR. 2006. The timing of early treatment: an overview. Am J Orthod Dentofacial 
334

335

336

337

338

339

340

341

342

343

344

345

346

347

348

349

350

351

352

353

354

355

356

357

358

359

360

Orthop 129:S47-49. DOI 10.1016/j.ajodo.2005.09.014.

Shalish M, Gal A, Brin I, Zini A, and Ben-Bassat Y. 2013. Prevalence of dental features that indicate a need for early orthodontic treatment. Eur J Orthod 35:454-459. DOI 10.1093/ejo/cjs011.

Soh J, Sandham A, and Chan YH. 2005. Occlusal status in Asian male adults: prevalence and ethnic variation. Angle Orthod 75:814-820. DOI 10.1043/00033219(2005)75[814:OSIAMA]2.0.C0;2.

Souames M, Bassigny F, Zenati N, Riordan PJ, and Boy-Lefevre ML. 2006. Orthodontic treatment need in French schoolchildren: an epidemiological study using the Index of Orthodontic Treatment Need. Eur J Orthod 28:605-609. DOI 10.1093/ejo/cjl045.

Steinmassl 0, Steinmassl PA, Schwarz A, and Crismani A. 2017. Orthodontic Treatment Need of Austrian Schoolchildren in the Mixed Dentition Stage. Swiss Dent J 127:122128.

Stenvik A, Espeland L, and Berg RE. 2011. A 57-year follow-up of occlusal changes, oral health, and attitudes toward teeth. Am J Orthod Dentofacial Orthop 139:S102-108. DOI 10.1016/j.ajodo.2009.12.030.

Tausche E, Luck 0, and Harzer W. 2004. Prevalence of malocclusions in the early mixed dentition and orthodontic treatment need. Eur J Orthod 26:237-244. DOI 10.1093/ejo/26.3.237.

Thilander B, Pena L, Infante C, Parada SS, and de Mayorga C. 2001. Prevalence of malocclusion and orthodontic treatment need in children and adolescents in Bogota, Colombia. An epidemiological study related to different stages of dental development. Eur J Orthod 23:153-167. DOI 10.1093/ejo/23.2.153.

Woon KC. 1988. Primary dentition occlusion in Chinese, Indian and Malay groups in Malaysia. Aust Orthod J 10:183-185.

Zhou X, Xu X, Li J, Hu D, Hu T, Yin W, Fan Y, and Zhang X. 2018. Oral health in China: from vision to action. Int J Oral Sci 10:1. DOI 10.1038/s41368-017-0006-6. 
361 Zhou X, Zhang Y, Wang Y, Zhang H, Chen L, and Liu Y. 2017. Prevalence of Malocclusion 362 in 3- to 5-Year-Old Children in Shanghai, China. Int J Environ Res Public Health 14. DOI 10.3390/ijerph14030328.

364 Zhou Z, Liu F, Shen S, Shang L, Shang L, and Wang X. 2016. Prevalence of and factors 365 affecting malocclusion in primary dentition among children in Xi'an, China. $B M C$ 366 Oral Health 16:91. DOI 10.1186/s12903-016-0285-x.

367 


\section{Table $\mathbf{1}$ (on next page)}

The definition of occlusal traits along with the criteria of malocclusion 


\begin{tabular}{|c|c|c|}
\hline Occlusal traits & Definition & Malocclusion \\
\hline \multicolumn{3}{|l|}{$\begin{array}{l}\text { 1. Sagittal } \\
\text { anomalies }\end{array}$} \\
\hline $\begin{array}{l}\text { 1.1 First permanent } \\
\text { molars }\end{array}$ & $\begin{array}{l}\text { Class I, the mesiobuccal cusp of the maxillary first } \\
\text { permanent molar occludes with the mesiobuccal } \\
\text { groove of the mandibular first permanent molar } \\
\text { (normal relation), or up to or equal to } 1 / 2 \text { cusp } \\
\text { width post-normal or pre-normal relation; Class II } \\
\text { (distal), more than } 1 / 2 \text { cusp width post-normal } \\
\text { relation; Class III (mesial), more than } 1 / 2 \text { cusp width } \\
\text { pre-normal relation. }\end{array}$ & Class III \\
\hline $\begin{array}{l}1.2 \text { Increased } \\
\text { overjet }\end{array}$ & $\begin{array}{l}\text { Distance of the most protruded maxillary incisor to } \\
\text { the corresponding mandibular incisor: } 0 \mathrm{~mm} \text {, edge- } \\
\text { to-edge (upper incisal edges touch lower edges when } \\
\text { biting); }>0 \mathrm{~mm}, \leq 3 \mathrm{~mm} \text {, normal; }>3 \mathrm{~mm}, \leq 5 \mathrm{~mm} \text {, } \\
\text { mild; }>5 \mathrm{~mm}, \leq 8 \mathrm{~mm} \text {, moderate; }>8 \mathrm{~mm} \text {, severe }\end{array}$ & $>3 \mathrm{~mm}$ \\
\hline $\begin{array}{l}1.3 \text { Anterior } \\
\text { crossbite }\end{array}$ & $\begin{array}{l}\text { One or more of the maxillary incisors/canine } \\
\text { occluded lingually to the mandibular } \\
\text { incisors/canine. }\end{array}$ & Present \\
\hline \multicolumn{3}{|l|}{$\begin{array}{l}\text { 2. Vertical } \\
\text { anomalies }\end{array}$} \\
\hline 2.1 Deep overbite & $\begin{array}{l}\text { Coverage of the mandibular incisors by most of the } \\
\text { maxillary incisors: }>0, \leq 1 / 3 \text {, normal; }>1 / 3, \leq 1 / 2 \text {, } \\
\text { mild; }>1 / 2, \leq 2 / 3 \text {, moderate; }>2 / 3 \text {, severe }\end{array}$ & $>2 / 3$ \\
\hline 2.2 Open bite & $\begin{array}{l}\text { Negative vertically overlapping between the } \\
\text { maxillary and the mandibular incisors: }>0, \leq 3 \mathrm{~mm} \text {, } \\
\text { mild; }>3 \mathrm{~mm}, \leq 5 \mathrm{~mm} \text {, moderate; }>5 \mathrm{~mm} \text {, severe }\end{array}$ & $>0 \mathrm{~mm}$ \\
\hline \multicolumn{3}{|l|}{$\begin{array}{l}\text { 3. Transversal } \\
\text { anomalies }\end{array}$} \\
\hline $\begin{array}{l}\text { 3.1 Midline } \\
\text { displacement }\end{array}$ & $\begin{array}{l}\text { Mandibular midline deviated } 2 \mathrm{~mm} \text { or more to the } \\
\text { maxillary midline }\end{array}$ & Present \\
\hline $\begin{array}{l}3.2 \text { Posterior } \\
\text { crossbite }\end{array}$ & $\begin{array}{l}\text { One or more of the maxillary molars occluded } \\
\text { lingually to the mandibular molars }\end{array}$ & Present \\
\hline 3.3 Scissors bite & $\begin{array}{l}\text { Maxillary molars occluded to the buccal surfaces of } \\
\text { the corresponding mandibular molars, and/or } \\
\text { mandibular molars occluded to the lingual surfaces } \\
\text { the corresponding maxillary molars }\end{array}$ & Present \\
\hline
\end{tabular}

\section{Space}




\section{discrepancies}

\begin{tabular}{|c|c|c|}
\hline $\begin{array}{l}4.1 \text { Crowding } \\
\text { (anterior, posterior; } \\
\text { maxillary, } \\
\text { mandibular) }\end{array}$ & $\begin{array}{l}>0 \mathrm{~mm}, \leq 2 \mathrm{~mm} \text {, mild; }>2 \mathrm{~mm}, \leq 4 \mathrm{~mm} \text {, moderate; }>4 \\
\mathrm{~mm} \text {, severe }\end{array}$ & $>2 \mathrm{~mm}$ \\
\hline $\begin{array}{l}4.2 \text { Anterior spacing } \\
\text { (maxillary, } \\
\text { mandibular) }\end{array}$ & $\begin{array}{l}>0 \mathrm{~mm}, \leq 2 \mathrm{~mm}, \text { mild; }>2 \mathrm{~mm}, \leq 4 \mathrm{~mm} \text {, moderate; }>4 \\
\mathrm{~mm} \text {, severe }\end{array}$ & $>4 \mathrm{~mm}$ \\
\hline
\end{tabular}

2 
Table 2 (on next page)

Prevalence of malocclusion in 7-9-year-old children in Shanghai 
1 Table 2. Prevalence of malocclusion in 7-9-year-old children in Shanghai

\begin{tabular}{cccccccc}
\hline & $\mathrm{n}$ & \multicolumn{2}{c}{ Normal Occlusion } & & \multicolumn{2}{c}{ Malocclusion } & \multirow{2}{*}{$P$} \\
Age (years) & & $\mathrm{n}$ & $\%$ & & $\mathrm{n}$ & $\%$ & \\
\hline 7 & 937 & 190 & 20.3 & & 747 & 79.7 & \\
8 & 1217 & 241 & 19.8 & & 976 & 80.2 & \\
9 & 656 & 148 & 25.6 & & 508 & 77.4 & \\
\hline Gender & & & & & & $0.624^{\text {a }}$ \\
Boys & 1479 & 310 & 21.0 & & 1169 & 79.0 & \\
Girls & 1331 & 269 & 20.2 & & 1062 & 79.8 & \\
\hline Total & 2810 & 579 & 20.6 & & 2231 & 79.4 & \\
\hline
\end{tabular}

2 a: chi-squared test. 


\section{Table 3(on next page)}

Composition and prevalence of sagittal occlusal characteristic in 7-9-years-old children in Shanghai 
Table 3 Composition and prevalence of sagittal occlusal characteristic in 7-9-years-old children in Shanghai.

\begin{tabular}{|c|c|c|c|c|c|c|c|c|c|}
\hline \multirow{2}{*}{$\begin{array}{l}\text { Sagittal Occlusal } \\
\text { Characteristic }\end{array}$} & \multicolumn{3}{|c|}{ Age (years) } & \multirow{2}{*}{$P$} & \multicolumn{2}{|c|}{ Sex } & \multirow{2}{*}{$P$} & \multicolumn{2}{|c|}{ Total } \\
\hline & 7 & 8 & 9 & & Boys & Girls & & $\mathrm{n}$ & $\%$ \\
\hline First permanent molar & & & & $0.017^{\mathrm{c}}$ & & & $0.361^{\mathrm{d}}$ & & \\
\hline Normal (Class I) & 404 (43.1\%) & 488 (40.1\%) & 298 (45.4\%) & & $647(43.7 \%)$ & $543(40.8 \%)$ & & 1190 & 42.3 \\
\hline Distal (Class II) & $474(50.6 \%)$ & $650(53.4 \%)$ & $306(46.6 \%)$ & & $734(49.6 \%)$ & $696(52.3 \%)$ & & 1430 & 50.9 \\
\hline Mesial (Class III) & $47(5.0 \%)$ & $68(5.6 \%)$ & $51(7.8 \%)$ & & $86(5.8 \%)$ & $80(6.0 \%)$ & & 166 & 5.9 \\
\hline Mixed $^{a}$ & $3(0.3 \%)$ & $4(0.3 \%)$ & $0(0.0 \%)$ & & $2(0.1 \%)$ & $5(0.4 \%)$ & & 7 & 0.2 \\
\hline Lost/Not erupted ${ }^{b}$ & $9(1.0 \%)$ & $7(0.6 \%)$ & $1(0.2 \%)$ & & $10(0.7 \%)$ & $7(0.5 \%)$ & & 17 & 0.6 \\
\hline Increased overjet & & & & $0.049^{\mathrm{d}}$ & & & $0.413^{\mathrm{d}}$ & & \\
\hline Edge to edge & $80(8.5 \%)$ & $97(8.0 \%)$ & $52(7.9 \%)$ & & $128(8.7 \%)$ & $101(7.6 \%)$ & & 229 & 8.1 \\
\hline Normal $(>0 \mathrm{~mm}, \leq 3 \mathrm{~mm})$ & 486 (51.9\%) & $604(49.6 \%)$ & 345 (52.6\%) & & $751(50.8 \%)$ & $684(51.4 \%)$ & & 1435 & 51.1 \\
\hline Mild ( $>3 \mathrm{~mm}, \leq 5 \mathrm{~mm}$ ) & $238(25.4 \%)$ & $275(22.6 \%)$ & $148(22.6 \%)$ & & $340(23.0 \%)$ & $321(24.1 \%)$ & & 661 & 23.5 \\
\hline Moderate $(>5 \mathrm{~mm}, \leq 8 \mathrm{~mm})$ & $99(10.6 \%)$ & $161(13.2 \%)$ & $80(12.2 \%)$ & & $190(12.8 \%)$ & $150(11.3 \%)$ & & 340 & 12.1 \\
\hline Severe $(>8 \mathrm{~mm})$ & $34(3.6 \%)$ & $80(6.6 \%)$ & $31(4.7 \%)$ & & $70(4.7 \%)$ & $75(5.6 \%)$ & & 145 & 5.2 \\
\hline Anterior crossbite & & & & $0.894^{d}$ & & & $0.876^{d}$ & & \\
\hline Absent & $836(89.2 \%)$ & 1093 (89.8\%) & $586(89.3 \%)$ & & 1325 (89.6\%) & $1190(89.4 \%)$ & & 2515 & 89.5 \\
\hline Present & $101(10.8 \%)$ & $124(10.2 \%)$ & $70(10.7 \%)$ & & $154(10.4 \%)$ & $141(10.6 \%)$ & & 295 & 10.5 \\
\hline
\end{tabular}


3 a: Child with Class II first molar relation on one side and Class III on the other side.

4 b: One or more first molars were missing or did not fully erupt.

5 c: Fisher's exact test.

6 d: chi-squared test. 


\section{Table 4(on next page)}

Composition and prevalence of vertical and transverse anomalies in 7-9-years-old children in Shanghai 
Table 4 Composition and prevalence of vertical and transverse anomalies in 7-9-years-old children in Shanghai.

\begin{tabular}{|c|c|c|c|c|c|c|c|c|c|}
\hline & \multicolumn{3}{|c|}{ Age (years) } & \multirow{2}{*}{$P$} & \multicolumn{2}{|c|}{ Sex } & \multirow{2}{*}{$P$} & \multicolumn{2}{|c|}{ Total } \\
\hline & 7 & 8 & 9 & & Boys & Girls & & $\mathrm{n}$ & $\%$ \\
\hline Deep overbite & & & & $0.127^{a}$ & & & $0.003^{a}$ & & \\
\hline None & $94(10.0 \%)$ & $133(10.9 \%)$ & $60(9.1 \%)$ & & $158(10.7 \%)$ & $129(9.7 \%)$ & & 287 & 10.2 \\
\hline Normal $(>0, \leq 1 / 3)$ & $451(48.1 \%)$ & $535(44.0 \%)$ & 307 (46.8\%) & & $629(42.5 \%)$ & $664(49.9 \%)$ & & 1293 & 46.0 \\
\hline Mild $(>1 / 3, \leq 1 / 2)$ & $216(23.1 \%)$ & $294(24.2 \%)$ & 137 (20.9\%) & & $366(24.7 \%)$ & $281(21.1 \%)$ & & 647 & 23.0 \\
\hline Moderate $(>1 / 2, \leq 2 / 3)$ & 117 (12.5\%) & $178(14.6 \%)$ & 115 (17.5\%) & & $226(15.3 \%)$ & $184(13.8 \%)$ & & 410 & 14.6 \\
\hline Severe $(>2 / 3)$ & $59(6.3 \%)$ & $77(6.3 \%)$ & $37(5.6 \%)$ & & $100(6.8 \%)$ & $73(5.5 \%)$ & & 173 & 6.2 \\
\hline Open bite & & & & $0.225^{b}$ & & & $0.222^{b}$ & & \\
\hline None & 890 (95.0\%) & $1162(95.5 \%)$ & 638 (97.3\%) & & $1420(96.0 \%)$ & $1270(95.4 \%)$ & & 2690 & 95.7 \\
\hline Mild $(>0, \leq 3 \mathrm{~mm})$ & $41(4.4 \%)$ & $52(4.3 \%)$ & $17(2.6 \%)$ & & $56(3.8 \%)$ & $54(4.1 \%)$ & & 110 & 3.9 \\
\hline Moderate $(>3, \leq 5 \mathrm{~mm})$ & $5(0.5 \%)$ & $3(0.2 \%)$ & $1(0.2 \%)$ & & $2(0.1 \%)$ & $7(0.5 \%)$ & & 9 & 0.3 \\
\hline Severe $(>5 \mathrm{~mm})$ & $1(0.1 \%)$ & $0(0.0 \%)$ & $0(0.0 \%)$ & & $1(0.1 \%)$ & $0(0.0 \%)$ & & 1 & 0.04 \\
\hline Midline displacement & $326(34.8 \%)$ & $469(38.5 \%)$ & $219(33.4 \%)$ & $0.052^{a}$ & $544(36.8 \%)$ & $470(35.3 \%)$ & $0.418^{a}$ & 1014 & 36.1 \\
\hline Posterior crossbite & $22(2.3 \%)$ & $29(2.4 \%)$ & $23(3.5 \%)$ & $0.280^{\mathrm{a}}$ & $41(2.8 \%)$ & $33(2.5 \%)$ & $0.628^{a}$ & 74 & 2.6 \\
\hline Scissors bite & $2(0.2 \%)$ & $11(0.9 \%)$ & $12(1.8 \%)$ & $0.003^{b}$ & $12(0.8 \%)$ & $13(1.0 \%)$ & $0.641^{\mathrm{a}}$ & 25 & 0.9 \\
\hline
\end{tabular}

2 a: chi-squared test.

3 b: Fisher's exact test. 


\section{Table 5 (on next page)}

Composition and prevalence of space discrepancies in 7-9-years-old children in Shanghai 
Table 5 Composition and prevalence of space discrepancies in 7-9-years-old children in Shanghai.

\begin{tabular}{|c|c|c|c|c|c|c|c|c|c|}
\hline & \multicolumn{3}{|c|}{ Age (years) } & \multirow{2}{*}{$P$} & \multicolumn{2}{|c|}{ Sex } & \multirow{2}{*}{$P$} & \multicolumn{2}{|c|}{ Total } \\
\hline & 7 & 8 & 9 & & Boys & Girls & & $\mathrm{n}$ & $\%$ \\
\hline $\begin{array}{l}\text { Maxillary anterior } \\
\text { crowding }\end{array}$ & & & & $<0.001^{\mathrm{a}}$ & & & $<0.001^{\mathrm{a}}$ & & \\
\hline None & $631(67.3 \%)$ & 727 (59.7\%) & $366(55.8 \%)$ & & $973(65.8 \%)$ & $751(56.4 \%)$ & & 1724 & 61.4 \\
\hline$>0, \leq 2 \mathrm{~mm}$ & $201(21.5 \%)$ & $311(25.6 \%)$ & $199(30.3 \%)$ & & $341(23.1 \%)$ & $370(27.8 \%)$ & & 711 & 25.3 \\
\hline$>2, \leq 4 \mathrm{~mm}$ & $92(9.8 \%)$ & $144(11.8 \%)$ & $68(10.4 \%)$ & & 127 (8.6\%) & $177(13.3 \%)$ & & 304 & 10.8 \\
\hline$>4 \mathrm{~mm}$ & $13(1.4 \%)$ & $35(2.9 \%)$ & $23(3.5 \%)$ & & $38(2.6 \%)$ & $33(2.5 \%)$ & & 71 & 2.5 \\
\hline $\begin{array}{l}\text { Maxillary } \\
\text { posterior } \\
\text { crowding }\end{array}$ & & & & $0.011^{\mathrm{b}}$ & & & $0.364^{b}$ & & \\
\hline None & $920(98.2 \%)$ & $1193(98.0 \%)$ & 655 (99.8\%) & & $1462(98.9 \%)$ & 1306 (98.1\%) & & 2768 & 98.5 \\
\hline$>0, \leq 2 \mathrm{~mm}$ & $14(1.5 \%)$ & $21(1.7 \%)$ & $1(0.2 \%)$ & & $14(0.9 \%)$ & $22(1.7 \%)$ & & 36 & 1.3 \\
\hline$>2, \leq 4 \mathrm{~mm}$ & $2(0.2 \%)$ & $2(0.2 \%)$ & $0(0.0 \%)$ & & $2(0.1 \%)$ & $2(0.2 \%)$ & & 4 & 0.1 \\
\hline$>4 \mathrm{~mm}$ & $1(0.1 \%)$ & $1(0.1 \%)$ & $0(0.0 \%)$ & & $1(0.1 \%)$ & $1(0.1 \%)$ & & 2 & 0.1 \\
\hline $\begin{array}{l}\text { Mandibular } \\
\text { anterior } \\
\text { crowding }\end{array}$ & & & & $0.006^{\mathrm{a}}$ & & & $<0.001^{\mathrm{a}}$ & & \\
\hline None & 373 (39.8\%) & $583(47.9 \%)$ & $313(47.7 \%)$ & & 736 (49.8\%) & $533(40.0 \%)$ & & 1269 & 45.2 \\
\hline$>0, \leq 2 \mathrm{~mm}$ & $330(35.2 \%)$ & 367 (30.2\%) & $212(32.3 \%)$ & & $444(30.0 \%)$ & $465(34.9 \%)$ & & 909 & 32.3 \\
\hline$>2, \leq 4 \mathrm{~mm}$ & $184(19.6 \%)$ & $204(16.8 \%)$ & 99 (15.1\%) & & 227 (15.3\%) & $260(19.5 \%)$ & & 487 & 17.3 \\
\hline$>4 \mathrm{~mm}$ & $50(5.3 \%)$ & $63(5.2 \%)$ & $32(4.9 \%)$ & & $72(4.9 \%)$ & 73 (5.5\%) & & 145 & 5.2 \\
\hline $\begin{array}{l}\text { Mandibular } \\
\text { posterior } \\
\text { crowding }\end{array}$ & & & & $0.141^{b}$ & & & $0.991^{\mathrm{a}}$ & & \\
\hline None & 917 (97.9\%) & $1191(97.9 \%)$ & $648(98.8 \%)$ & & $1450(98.0 \%)$ & 1306 (98.1\%) & & 2756 & 98.1 \\
\hline$>0, \leq 2 \mathrm{~mm}$ & $11(1.2 \%)$ & $15(1.2 \%)$ & $1(0.2 \%)$ & & $15(1.0 \%)$ & $12(0.9 \%)$ & & 27 & 1.0 \\
\hline
\end{tabular}




\begin{tabular}{|c|c|c|c|c|c|c|c|c|}
\hline$>2, \leq 4 \mathrm{~mm}$ & $7(0.7 \%)$ & $9(0.7 \%)$ & $7(1.1 \%)$ & $12(0.8 \%)$ & $11(0.8 \%)$ & & 23 & 0.8 \\
\hline$>4 \mathrm{~mm}$ & $2(0.2 \%)$ & $2(0.2 \%)$ & $0(0)$ & $2(0.1 \%)$ & $2(0.2 \%)$ & & 4 & 0.1 \\
\hline $\begin{array}{l}\text { Maxillary anterior } \\
\text { spacing }\end{array}$ & & & & & & $<0.001^{\mathrm{a}}$ & & \\
\hline None & $487(52.0 \%)$ & $760(62.4 \%)$ & $434(66.2 \%)$ & 841 (56.9\%) & $840(63.1 \%)$ & & 1681 & 59.8 \\
\hline$>0, \leq 2 \mathrm{~mm}$ & $244(26.0 \%)$ & 277 (22.8\%) & $128(19.5 \%)$ & $356(24.1 \%)$ & $293(22.0 \%)$ & & 649 & 23.1 \\
\hline$>2, \leq 4 \mathrm{~mm}$ & $115(12.3 \%)$ & $102(8.4 \%)$ & $39(5.9 \%)$ & $137(9.3 \%)$ & $119(8.9 \%)$ & & 256 & 9.1 \\
\hline$>4 \mathrm{~mm}$ & $91(9.7 \%)$ & $78(6.4 \%)$ & $55(8.4 \%)$ & $145(9.8 \%)$ & $79(5.9 \%)$ & & 224 & 8.0 \\
\hline $\begin{array}{l}\text { Mandibular } \\
\text { anterior spacing }\end{array}$ & & & & & & $0.081^{a}$ & & \\
\hline None & $734(78.3 \%)$ & $948(77.9 \%)$ & $523(79.7 \%)$ & 1136 (76.8\%) & $1069(80.3 \%)$ & & 2205 & 78.5 \\
\hline$>0, \leq 2 \mathrm{~mm}$ & $129(13.8 \%)$ & $183(15.0 \%)$ & $82(12.5 \%)$ & $216(14.6 \%)$ & 178 (13.4\%) & & 394 & 14.0 \\
\hline$>2, \leq 4 \mathrm{~mm}$ & $51(5.4 \%)$ & $52(4.3 \%)$ & $23(3.5 \%)$ & 75 (5.1\%) & $51(3.8 \%)$ & & 126 & 4.5 \\
\hline$>4 \mathrm{~mm}$ & $23(2.5 \%)$ & $34(2.8 \%)$ & $28(4.3 \%)$ & $52(3.5 \%)$ & $33(2.5 \%)$ & & 85 & 3.0 \\
\hline
\end{tabular}

2 a: chi-squared test.

b: Fisher exact test. 